\title{
The Role of 16s rDNA PCR in the Diagnosis of Peritoneal Dialysis-Associated Peritonitis
}

Holly L. Ciesielczuk ${ }^{1}$, Robert J. Shorten ${ }^{1}$, Andrew Davenport ${ }^{2}$, Hala Kandil' ${ }^{1}$, Jane E. Carpenter ${ }^{3}$, Timothy D. McHugh ${ }^{4}$ and Sophie E. Collier ${ }^{1 *}$

${ }^{1}$ Department of Microbiology, Royal Free London NHS Foundation Trust, London, United Kingdom

${ }^{2}$ Department of Nephrology, Royal Free London NHS Foundation Trust, London, United Kingdom

${ }^{3}$ Department of Microbiology, West Middlesex University, Isleworth, United Kingdom

${ }^{4}$ Centre of Clinical Microbiology, Department of Infection and Immunity, University College London, United Kingdom

\begin{abstract}
Introduction: Despite recent advances in peritoneal dialysis (PD), peritonitis remains the most common and serious complication. In a significant proportion of patients a pathogen is not cultured. In this study we investigated the use of 16S rDNA PCR to make a bacterial diagnosis.

Methods: We used an optimised DNA extraction and 16S rDNA PCR with DNA sequencing to detect pathogens in peritoneal dialysis-associated peritonitis (PDAP).

Results: Seventy-one PD fluids from twenty-four patients were analysed. In suspected cases of PDAP, thirteen out of twenty-one patients had a bacterial pathogen cultured and 16S rDNA PCR with DNA sequencing identified one additional pathogen. However 16S rDNA PCR only detected the pathogen in five of the culture-positive fluids. All follow-up samples were culture-negative, but possible pathogens were identified in three samples by the 16S rDNA PCR.
\end{abstract}

In suspected cases of PDAP the sensitivity and specificity of the PCR was calculated as $69 \%$ and $63 \%$, respectively.

Conclusion: The use of $16 \mathrm{~S}$ rDNA PCR in diagnosing PDAP needs further study and improved sensitivity before widespread introduction.

Keywords: Clinical Microbiology; Detection; Diagnostic Techniques

Abbreviations: CoNS - Coagulase Negative Staphylococcus; Ct - Cycle Threshold; HRM - High Resolution Melt; NPV - Negative Predictive Value; PD - Peritoneal Dialysis; PDAP - Peritoneal DialysisAssociated Peritonitis; PPV - Positive Predictive Value; RFH - Royal Free Hospital; WBC - White Blood Cell; WCC - White Cell Count.

\section{Introduction}

Despite the success and advances in peritoneal dialysis (PD) significant complications still remain and one of the most common is peritonitis, which can have serious clinical implications. Peritoneal dialysis-associated peritonitis (PDAP) is caused by bacteria or fungi transmitted to the peritoneal cavity via the catheter (primary peritonitis) or less commonly from the gastrointestinal tract after perforation (secondary peritonitis). PDAP is a leading cause of morbidity and mortality in PD patients, also causing $30-50 \%$ of technical failures [1]. Despite the reported reduction in PDAP cases, the mortality rate has not decreased from 25.3 deaths per 100 patient years or 1-6\% PD patients in recent years $[2,3]$.

PDAP is defined as having cloudy or turbid peritoneal fluid, more than 100 white blood cells (WBC) per ml PD fluid (with over 50\% neutrophils), with or without fever and abdominal pain [4]. To date, the gold standard for identifying pathogens in PD fluids is culture, but PDAP is usually treated empirically due to its serious nature. Antibiotic treatment provides broad coverage as $67 \%$ PDAP cases are due to Gram-positive organisms, 28\% by Gram-negative organisms and 5\% by fungi and anaerobes. Staphylococcus aureus and Staphylococcus epidermidis are the two most common bacterial causes of PDAP $[5,6]$.

As peritonitis continues to be a major problem, the International Society for Peritoneal Dialysis (ISPD) has established guidelines to decrease infection rates: each renal unit should aim to have less than one episode of peritonitis per 18 patient months in adults, with a primary cure rate of more than $80 \%$ and a culture-negative rate below 20\% [7]. Culture-negative peritonitis remains a clinical issue with centres reporting rates between 13 and 55\% [8,9]. Causative factors include previous antibiotic treatment and infection with a fastidious organism such as Campylobacter species [10,11]. In many cases, the reasons for why an organism is not cultured are unclear and the underlying microbiology is poorly understood, despite patients responding to antibiotics targeting Gram-positive organisms [8]. In this group of patients, 16S rDNA PCR could prove to be a useful and insightful technique.

Several laboratories have investigated the use of PCR to rapidly detect and identify bacterial pathogens and thus increase the diagnostic yield in PDAP. These assays target the $16 \mathrm{~S}$ rRNA or $23 \mathrm{~S}$ rRNA genes, as they are universal to all bacteria, but variable enough for species identification. Johnson et al [12] and Yoo et al [13] demonstrated that despite the satisfactory correlation between PCR and culture results, its diagnostic potential in culture-negative samples was affected by suboptimal sensitivity and specificity rates.

Therefore, we aimed to improve on these results by optimising the DNA extraction and using real-time PCR with melt curve analysis. By collecting data on patient treatment and outcome we also hoped to see if the technique could help to predict failure or delayed response

*Corresponding author: Sophie Collier, Department of Microbiology, Royal Free Hospital, Pond Street, London NW3 2QG, United Kingdom, Tel: 02077940500 \#38282; E-mail: sophiecollier@nhs.net

Received September 27, 2012; Accepted October 19, 2012; Published October 22, 2012

Citation: Ciesielczuk HL, Shorten RJ, Davenport A, Kandil H, Carpenter JE, McHugh TD, et al. (2012) The Role of 16s rDNA PCR in the Diagnosis of Peritoneal DialysisAssociated Peritonitis. J Med Microb Diagn 1:116. doi:10.4172/2161-0703.1000116

Copyright: (c) 2012 Collier SE, et al. This is an open-access article distributed under the terms of the Creative Commons Attribution License, which permits unrestricted use, distribution, and reproduction in any medium, provided the original author and source are credited. 
to treatment in those patients where the $16 \mathrm{~S}$ rDNA PCR remained positive.

\section{Materials and Methods}

\section{Study Population}

Between March and August of 2009 seventy-one consecutive PD fluids from 24 patients were received and processed by the Microbiology Department of the Royal Free Hospital (RFH). These PD fluids represented 21 clinically suspected episodes of PDAP and 50 follow-up samples from PDAP patients. Suspected cases were defined as those with cloudy bags and/or abdominal pain, or other suggestive abdominal symptoms such as vomiting. The diagnosis of PDAP was confirmed if the WCC was over $100 / \mathrm{ml}$. Follow up samples were sent routinely within 3 days of the initial diagnosis to monitor response and then at 7 days when the patients were reviewed, often as outpatients. For all follow up samples the patients were on antibiotic therapy.

The antibiotic therapy used and outcome measures were collected for each patient retrospectively. The outcome measures collected were changes to antibiotic therapy, catheter removal and patient being transferred to haemodialysis.

\section{Study Specimen}

A total of $20-30 \mathrm{ml}$ PD fluid was received in the microbiology laboratory. A $10 \mathrm{ml}$ aliquot of the fluid was processed according to the standard operating procedure of the department. A haematocrit cell count was performed prior to centrifugation of the sample at 2,500 $\mathrm{x}$ $\mathrm{g}$ for 3 minutes and a Gram stain was prepared from the deposit. The deposit was re-suspended in $10 \mathrm{ml}$ sterile distilled water before being cultured on blood agar, chocolate agar and anaerobic agar for 48 hours.

\section{DNA Extraction Optimisation}

The remaining $10-20 \mathrm{ml} \mathrm{PD}$ fluid was heat-killed at $80^{\circ} \mathrm{C}$ for 20 minutes and the fluid centrifuged at $2,500 \times \mathrm{g}$ for 30 minutes to pellet the cells and bacteria. The pellet underwent DNA extraction.

To determine the most appropriate DNA extraction procedure we compared: QIAmp DNA minikit (Qiagen), Wizard ${ }^{\circledR}$ genomic DNA purification kit (Promega), GeneOhm ${ }^{\mathrm{TM}}$ lysis kit (BD), a modified Chelex extraction as described by Walsh et al [14] and a crude boil extraction. In the Chelex method, the cells in the centrifuged pellet were broken open by vortexing with $10 \% \mathrm{w} / \mathrm{v}$ chelex and washed with phosphate buffered saline. A final centrifugation step pelleted the cell debris leaving the DNA in the supernatant. For all methods, the supernatant was transferred to a fresh tube and used for the PCR. Sterile PD fluid, in $10 \mathrm{ml}$ aliquots, underwent UV irradiation for 20 minutes and was spiked with Staphylococcus aureus (ATCC 49619) cells to give an optical density of 2 McFarland and a 1:10 serial dilution set prepared. The aliquots were subjected to each of the extraction methods, in duplicate, and analysed by real-time $16 \mathrm{~S}$ rDNA PCR. The cycle threshold $(\mathrm{Ct})$ values for each dilution were used to determine the most sensitive extraction method.

Once the modified Chelex method was identified as the preferred extraction protocol for isolating low quantities of DNA, the optimal volume fluid for maximum DNA recovery was established. Spiked volumes of $10,20,50$ and $100 \mathrm{ml}$ were centrifuged, the DNA extracted and PCR results used to determine the optimal volume. Comparison of Ct values identified $20 \mathrm{ml}$ as the preferred volume of PD fluid required for optimum DNA recovery and amplification.

\section{Real-Time 16S rDna PCR Assay}

PD fluids were subjected to the two (762/598bp) fragment 16S rDNA PCR assay recently described by Jenkins et al [15], which uses the primers described by Xu et al [16] and listed in Table 1. We converted the PCR assay to a real-time format with a high-resolution melt (HRM) point analysis to confirm positive amplification. Streptococcus pneumonia (ATCC 49619) DNA was used as the positive control and PCR-grade water was used as the negative control.

Each PCR reaction contained $12.5 \mu$ l Platinum ${ }^{\circ} \mathrm{SYBR}^{\star}$ green $\mathrm{qPCR}$ supermix-UDG (Invitrogen, UK), $0.5 \mu \mathrm{M}$ forward and reverse primer, and $5 \mu \mathrm{l}$ template DNA made up to a final volume of $20 \mu \mathrm{l}$ with PCRgrade water. A separate reaction was prepared for each of the two gene fragments. The PCR conditions consisted of denaturation at $95^{\circ} \mathrm{C}$ for 2 minutes followed by 35 cycles each consisting of denaturation at $96^{\circ} \mathrm{C}$ for 60 seconds, annealing at $55^{\circ} \mathrm{C}$ for 60 seconds and extension at $72^{\circ} \mathrm{C}$ for 60 seconds. The final elongation step was prolonged at $72^{\circ} \mathrm{C}$ for 10 minutes.

Post DNA amplification the HRM analysis was performed consisting of an elevation in temperature from $65^{\circ} \mathrm{C}$ to $95^{\circ} \mathrm{C}$, with the temperature increasing by $1^{\circ} \mathrm{C}$ at 5 second intervals. DNA denaturation (melt) was detected by the emitted fluorescence at $510 \mathrm{~nm}$.

A cut-off of 30 cycles and a threshold of 0.05 were used to distinguish between positive and negative PD fluids. DNA denaturation during the $\mathrm{HRM}$ occurred at $86^{\circ} \mathrm{C} \pm 0.5$ (762bp fragment) and $87^{\circ} \mathrm{C} \pm 0.2$ (598bp fragment) for all positive samples. A PD fluid was considered positive if one or more of the $16 \mathrm{~S}$ gene fragments was detected. These fragments underwent DNA sequencing, as described previously [15].

\section{Ethics}

Approval was granted by the Local Ethics Committee, as the study was looking at service development. PCR and DNA sequencing results were shared with the clinical team retrospectively and not recorded in the patients' notes.

\section{Results}

Seventy-one PD fluids, from 24 patients, were analysed by routine culture methods and $16 \mathrm{~S}$ rRNA PCR with DNA sequencing. Twentyone PD fluid samples were taken from clinically suspected cases of PDAP and the remaining 50 were collected during follow-up of a peritonitis episode. 3 patients only had follow up samples included in the study.

\section{Suspected cases of PDAP}

Twenty PD patients presented to the renal unit with symptoms suggestive of peritonitis. One patient presented on two separate occasions, resulting in a total of 21 suspected cases of peritonitis. The culture, PCR and DNA sequencing results are summarised in the results tree below (Figure 1). Table 2 lists the bacteria isolated from those patients by either culture, or PCR and sequencing, or both.

Of the 13 culture-positive PD fluids, the 16S rDNA assay only confirmed the result in five samples and failed to detect the remaining seven pathogens. In the one mixed culture infection the assay identified the Acinetobacter species, but not the CoNS, and it identified $A$. altamirensis in one sample, which isolated $O$. anthropi by culture. In the culture-negative samples, PCR did detect one pathogen (CoNS), but in the other sample an environmental contaminant (Denitratisoma

\begin{tabular}{|l|l|l|}
\hline Primer & Primer pair & Sequence $\mathbf{5}^{\prime} \mathbf{-}$ ' \\
\hline XB1 & 762bp forward & CAGACTCCTACGGGGAGGCAGCAGT \\
\hline PSR & 762bp reverse & ACTTAACCCAACATCTCACGACAC \\
\hline PSL & 598bp forward & AGGATTAGATACCCTGGTAGTCCA \\
\hline XB4 & 598bp reverse & GTGTGTACAAGGCCCGGGAAC \\
\hline
\end{tabular}

Table 1: Forward and reverse primer pairs for the short-fragment $16 S$ rRNA PCR. 


\begin{tabular}{|l|l|l|}
\hline WCC (per $\mathbf{~ m l )}$ & Culture result & Sequencing result \\
\hline 2 & Negative & Denitratisoma spp \\
\hline 243 & CoNS & Negative \\
\hline 394 & CoNS & CoNS \\
\hline 9 & CoNS & Negative \\
\hline 25 & CoNS & CoNS \\
\hline 6440 & CoNS & CoNS \\
\hline 60 & Streptococcus oralis & Negative \\
\hline 143 & Negative & CoNS \\
\hline 2240 & CoNS \& Acinetobacter spp & Acinetobacter spp \\
\hline 1360 & Rothia spp & Negative \\
\hline 8640 & CoNS & Negative \\
\hline 4400 & Streptococcus pneumoniae & Negative \\
\hline 535 & Ochrobacter anthropi & Aurantimonas altamirensis \\
\hline 2440 & Kocuria kristinae & Negative \\
\hline 265 & CoNS & CoNS \\
\hline
\end{tabular}

*WCC - White Cell Count, CoNS - Coagulase-Negative Staphylococcus, sppSpecies

Table 2: Culture and DNA sequencing results for suspected cases of PDAP.

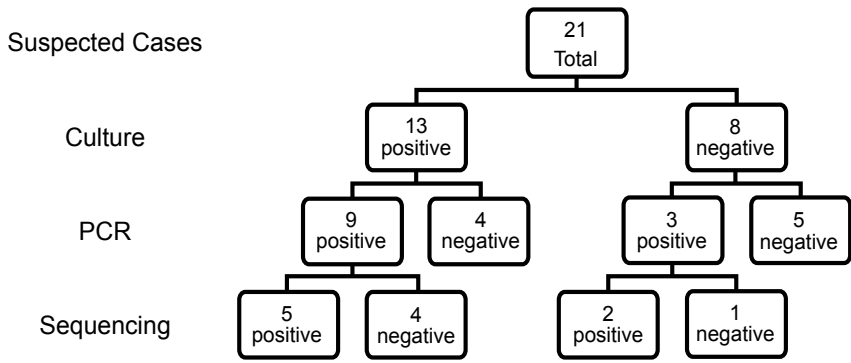

Figure 1: Results summary for PD fluids from suspected cases of PDAP.

spp) was detected.

The culture-negative rate was $38 \%$ for all suspected cases of PDAP. However, the rate was reduced to $29 \%$ for the suspected cases of PDAP with a WCC greater than $100 / \mathrm{ml}$.

In the suspected cases of PDAP the sensitivity and specificity of the $16 \mathrm{~S}$ rDNA assay compared to routine culture was calculated as $69 \%$ and $63 \%$, respectively. The positive predictive value (PPV) and negative predictive value (NPV) were calculated as $75 \%$ and $56 \%$, respectively.

\section{Follow-Up Samples from PD Patients}

The culture, PCR and DNA sequencing results are summarised in the results tree below (Figure 2). The bacteria identified by PCR and sequencing are listed in Table 3.

Fifty PD fluids were collected as part of the routine follow-up of 24 PD patients after an episode of PDAP. Forty fluids had a WCC less than $100 / \mathrm{ml}$, as expected. The others still had a WBC greater than $100 / \mathrm{ml}$, but the trend was downwards.

All follow-up PD fluids were culture-negative. Twenty-one were PCR-positive, but only 12 of these identified a bacterium by DNA sequencing. The majority of the bacteria identified were considered environmental contaminants or not clinically relevant.

Three Acinetobacter species were identified in samples with WCC less than $100 / \mathrm{ml}$.

The sensitivity and specificity were calculated again for the followup PD fluids and found to be $0 \%$ and $58 \%$, respectively. The PPV was $0 \%$ and the NPV $100 \%$, but without a positive reference these calculations need confirmation.

The most common isolates were coagulase-negative Staphylococcus species. The second most common isolate was Acinetobacter species, but three of these gram negative isolates were in follow up samples. Otherwise Gram-positive organisms predominated with Streptococcus species, Rothia species and Kocuria species also being isolated.

All PD patients presenting with a suspected episode of PDAP were treated empirically with intraperitoneal (IP) cefradine and gentamicin. Antibiotics were changed according to the culture results, with all episodes of CoNS-related PDAP being treated with IP vancomycin; S. pneumoniae with IP amoxicillin; and Gram-negative peritonitis with IP aztreonam and oral ciprofloxacin. All patients responded to the antibiotics administered. Four patients were subsequently converted to haemodialysis: two due to repeat infections with different organisms (which included CNS and Streptococcus oralis) and two due to the inadequacy of PD. Three of these four patients also had their catheters removed, but there was no evidence of bacterial infection or colonisation.

\section{Discussion}

In this study we monitored PD samples to determine whether realtime PCR could detect bacteria, particularly in those patients where a bacteria was not cultured, and also to see if the technique could predict failure or delayed response to treatment. Although sensitivity was suboptimal, the results would suggest a good negative predictive value and therefore a possible role for this assay in excluding bacterial infection from PDAP. A negative PCR result would then encourage clinicians to look for other possible causes of a raised WCC, such as endotoxin

Follow-up Samples

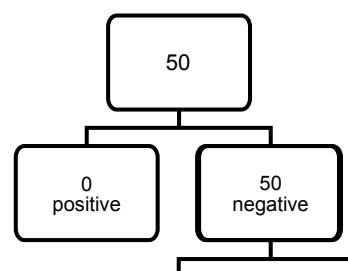

PCR

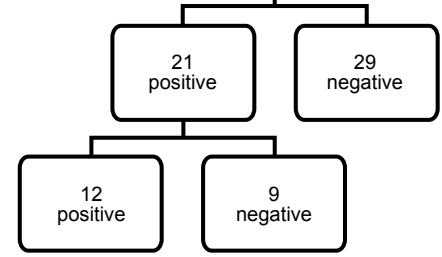

Sequencing

Figure 2: Results summary for follow-up PD fluids.

\begin{tabular}{|l|l|l|}
\hline WCC $($ per $\mathbf{m l})$ & Culture result & Sequencing result \\
\hline 1 & Negative & Massilia spp \\
\hline$<1$ & Negative & Oxalobacter $\mathrm{spp}$ \\
\hline$<1$ & Negative & Sphingomonas $\mathrm{spp}$ \\
\hline 50 & Negative & Acinetobacter $\mathrm{spp}$ \\
\hline 6 & Negative & Massilia spp \\
\hline 20 & Negative & Sphingomonas $\mathrm{spp}$ \\
\hline 96 & Negative & Massilia $\mathrm{spp}$ \\
\hline 4 & Negative & Acidovorax $\mathrm{spp}$ \\
\hline$<1$ & Negative & Acinetobacter $\mathrm{spp}$ \\
\hline 31 & Negative & Sphingomonas $\mathrm{spp}$ \\
\hline 3 & Negative & Sphingomonas $\mathrm{spp}$ \\
\hline 11 & Negative & Acinetobacter $\mathrm{spp}$ \\
\hline
\end{tabular}

Table 3: Positive PCR results for the follow-up samples. 
[17] or malignancy, and perform a cytological examination of the peritoneal fluid to determine the new diagnosis [18]. Clinicians should also consider the possibility of other infectious agents, which would not be detected by the $16 \mathrm{~S}$ rDNA PCR or standard culture, such as a slow growing fungus or Mycobacterium sp.

All follow-up samples were culture-negative and taken after empirical antibiotics were started. PCR detected a wide range of environmental bacteria in the group of follow up samples. There is a possibility that although these bacteria have not been reported as pathogens yet, they could play a role in PDAP. However, if they were primary pathogens they should have been detected in the initial samples from suspected cases of PDAP rather than in the follow-up samples. This led to the suspicion that they are contaminants for which possible sources include the PCR reagents, including Taq polymerase. We used Taq from assured DNA free sources and have performed in house testing on a range of Taqs and also treatment with UV prior to use. Also our negative control which we ran with master mix and Taq but no sample remained negative. Our experience is that the gain in reduced contamination following UV treatment is outweighed by a loss of sensitivity of the amplification.

Interestingly, the $16 \mathrm{~S}$ rDNA assay did detect Acinetobacter species in three different follow-up samples. Acinetobacter species are known to cause infection, especially in healthcare-associated settings $[19,20]$. Therefore, it is possible that the assay had detected three potential new episodes of PDAP. However, as these patients had a low WCC and had responded to treatment, which included IP gentamicin (which should be effective against Acinetobacter), it is likely that these isolates are contaminants or non-viable organisms. The $16 \mathrm{~S}$ rDNA PCR results would not have changed treatment in these patients.

In both groups of patients (suspected and follow up) several samples gave a positive signal but did not generate any signal data. This is not uncommon in assays that rely on conserved sequences across species barriers. A common problem is that primers are not a good match to the priming sites in the species concerned, so this can lead to mis-priming. Possible outcomes of mis-priming are no product at all being formed or, alternatively, priming from multiple sites across the target gene, resulting in a heterogeneous population of amplimers which cannot be distinguished by the sequencer.

The cost of culturing a sample versus analysing it by $16 \mathrm{~S}$ rDNA PCR and DNA sequencing also highlights another disadvantage of the 16S rDNA assay. Standard solid culture of a PD fluid costs less than $£ 1$ per agar plate, blood culture costs approximately $£ 6$ per sample and $16 \mathrm{~S}$ rRNA PCR reagents cost approximately $£ 5$, but due to the staffing requirements for this procedure the overall total cost is estimated at $£ 70$.

Previous studies have demonstrated the benefit of $16 \mathrm{~S}$ rDNA PCR over culture in providing a rapid diagnosis, such as in cerebrospinal fluid, brain abscesses and emphysemas'. [21,22] Speed of diagnosis remains an advantage of this $16 \mathrm{~S}$ rDNA PCR over culture in diagnosing PDAP, if sensitivity could be improved.

In our study the $16 \mathrm{~S}$ rDNA assay failed to detect all the bacteria isolated by culture in suspected cases of PDAP and was only able to detect one additional CoNS in this group of patients. This reduces its value as a primary diagnostic test compared to standard culture methods. PCR is known to be inhibited by components of blood cells, such as haemoglobin and lactoferrin, so it is possible that some of these samples could have been inhibited and therefore PCR-negative [23,24]. In six of the samples from suspected cases of PDAP, where the patients had a high WCC $(>200 / \mathrm{ml})$, they were culture-positive, but PCRnegative. It may be that the high white cell count confounded either the DNA extraction or the amplification reaction.

\section{Conclusions}

Even with the advances in molecular diagnostics in recent years, culture remains the gold standard for laboratory diagnosis of PDAP. Despite improvements in the DNA extraction procedure and the rapid nature of the $16 \mathrm{~S}$ rDNA PCR assay in this study, the molecular assay failed to improve on the culture-positive rate of PD fluids.

\section{References}

1. Davenport A (2009) Peritonitis remains the major clinical complication of peritoneal dialysis: the London, UK, peritonitis audit 2002-2003. Perit Dial Int 29: 297-302.

2. Bloembergen WE, Port FK, Mauger EA, Wolfe RA (1995) A comparison of mortality between patients treated with hemodialysis and peritoneal dialysis. $J$ Am Soc Nephrol 6: 177-183.

3. Fried LF, Bernardini J, Johnston JR, Piraino B (1996) Peritonitis influences mortality in peritoneal dialysis patients. J Am Soc Nephrol 7: 2176-2182

4. Van Biesen W, Veys N, Vanholder R, Lameire N (2002) Peritoneal-dialysisrelated peritonitis: the art of rope-dancing. Nephrol Dial Transplant 17: 18781882.

5. Kent JR, Almond MK (2000) A survey of CAPD peritonitis management and outcomes in north and south Thames NHS regions (U.K.): support for the ISPD guidelines. International society for peritoneal dialysis. Perit Dial Int 20: 301 305

6. Troidle L, Finkelstein F (2006) Treatment and outcome of CPD-associated peritonitis. Ann Clin Microbiol Antimicrob 5: 6.

7. Li PK, Szeto CC, Piraino B, Bernardini J, Figueiredo AE, et al. (2010) Peritonea dialysis-related infections recommendations: 2010 update. Perit Dial Int 30: 393-423.

8. Ghali JR, Bannister KM, Brown FG, Rosman JB, Wiggins KJ, et al. (2011) Microbiology and outcomes of peritonitis in Australian peritoneal dialysis patients. Perit Dial Int 31: 651-652.

9. Najafi I, Ossareh S, Hosseini M, Ganji MR, Naghibi M, et al. (2011) Epidemiology of culture-negative peritonitis in Iranian patients on continuous ambulatory peritoneal dialysis. Iran J Kidney Dis 5: 332-337.

10. Fahim M, Hawley CM, McDonald SP, Brown FG, Rosman JB, et al. (2010) Culture-negative peritonitis in peritoneal dialysis patients in Australia: predictors, treatment, and outcomes in 435 cases. Am J kidney Dis 55: 690-697.

11. Elshafie SS, Asim M, Ashour A, Elhiday AH, Mohsen T, et al. (2010) Campylobacter peritonitis complicating continuous ambulatory peritoneal dialysis: report of three cases and review of the literature. Perit Dial Int 30: 99-104.

12. Johnson G, Wilks M, Warwick S, Millar MR, Fan SL (2006) Comparative study of diagnosis of PD peritonitis by quantitative polymerase chain reaction for bacterial DNA vs culture methods. J Nephrol 19: 45-49.

13. 13. Yoo TH, Chang KH, Ryu DR, Kim JS, Choi HY, et al. (2006) Usefulness of 23S rRNA amplification by PCR in the detection of bacteria in CAPD peritonitis. Am J Nephrol 26: 115-120.

14. Walsh PS, Metzger DA, Hiquchi R (1991) Chelex 100 as a medium for simple extraction of DNA for PCR-based typing from forensic material. Biotechniques 10: $506-513$

15. Jenkins C, Ling CL, Ciesielczuk HL, Lockwood J, Hopkins S, et al. (2012) Detection and identification of bacteria in clinical samples by $16 \mathrm{~S}$ rRNA gene sequencing: comparison of two different approaches in clinical practice. J Med Microbiol 61: 483-488.

16. Xu J, Smyth CL, Buchanan JA, Dolan A, Rooney PJ, et al. (2004) Employment of $16 \mathrm{~S}$ rDNA gene sequencing techniques to identify culturable environmental eubacteria in a tertiary referral hospital. J Hosp Infect 57: 52-58. 
Citation: Collier SE, Ciesielczuk HL, Shorten RJ, Davenport A, Kandil H, et al. (2012) The Role of 16s rDNA PCR in the Diagnosis of Peritoneal Dialysis-Associated Peritonitis. J Med Microb Diagn 1:116. doi:10.4172/2161-0703.1000116

17. Martis L, Patel M, Giertych J, Mongoven J, Taminne M, et al. (2005) Aseptic peritonitis due to peptidoglycan contamination of pharmacopoeia standard dialysis solution. Lancet 365: 588-594.

18. de Freitas DG, Gokal R (2005) Sterile peritonitis in the peritoneal dialysis patient. Perit Dial Int 25: 146-151.

19. Baang JH, Axelrod P, Decker BK, Hujer AM, Dash G, et al (2012) Longitudinal epidemiology of multidrug-resistant (MDR) Acinetobacter species in a tertiary care hospital. Am J Infect Control 40: 134-137.

20. Borras M, Moreno S, Garcia M, Martin M, Manonelle A, et al. (2007) Acinetobacter junii causes refractory peritonitis in a patient on automated peritoneal dialysis. Perit Dial Int 27: 101-102.
21. Kupila L, Rantakokko-Jalava K, Jalaya J, Nikkari S, Peltonen R, et al. (2003) Aetiological diagnosis of brain abscesses and spinal infections: application of broad range bacterial polymerase chain reaction analysis. J Neurol Neurosurg Psychiatry 74: 728-733.

22. Saglani S, Harris KA, Wallis C, Hartley JC (2005) Empyema: the use of broad range 16S rDNA PCR for pathogen detection. Arch Dis Child 90: 70-73.

23. Al-Soud WA, Radstrom P (2001) Purification and characterization of PCRinhibitory components in blood cells. J Clin Microbiol 39: 485-493.

24. de Vries JE, Wijnen PAHM, Hamulyak K, van Dieijen-Visser MP, Bekers O (2001) PCR on cell lysates obtained from whole blood circumvents DNA isolation. Clin Chem 47: 1701-1702. 